\title{
Professor Valery M. Yermachenko 70-year Jubilee
}

PACS numbers: $01.60 .+\mathrm{q}$

DOI: $10.1134 / \mathrm{S} 1054660 \mathrm{X} 09150134$

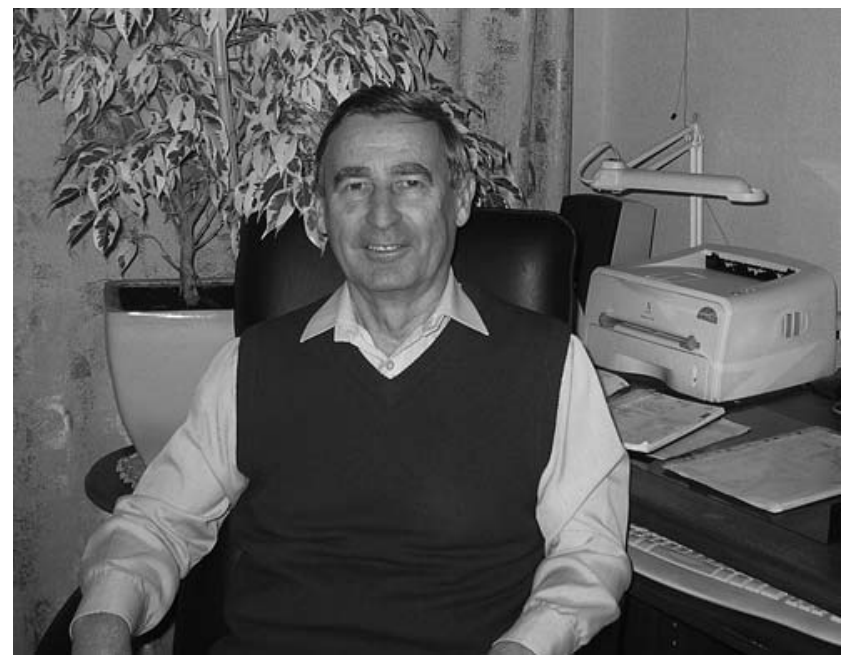

The Editorial Board of the journal Laser Physics is happy to congratulate its Member Professor Valery M. Yermachenko with his 70-year Jubilee.

Valery M. Yermachenko was born on August 3, 1939 in Stalingrad (now Volgograd). After graduating from the school in 1956, he entered the Moscow Engineering Physics Institute. In the third year of his studies, he joined the theoretical group. He accomplished his diploma in the All-Union Scientific Research Institute of Experimental Physics. His first scientific paper was published in 1962 (co-authored with Y.B. Zeldovich) in the Journal of Experimental and Theoretical Physics. In 1964, Valery Yermachenko returned to the Moscow Engineering Physics Institute, joining the Department of Theoretical Nuclear Physics, where he works till the present time. He got his Ph.D. degree in 1968 and the Dr. Sci. degree in 1982. Since 1985, he is a Professor.

In 1972-1973, Valery Yermachenko was a Researcher in the Laboratoir de Spectroscopie Hertzienne de l'École Normale Supérieure in Paris, France. And in 1989 he worked in the Department of Physics and Astronomy of the University of Rochester, USA.
The scientific interests of Professor Yermachenko are in the field of laser physics. His works on the physics of lasers, nonlinear and coherent optics, and the theory of atomic collisions are world-widely known and highly appreciated. He published more than 150 papers and review articles in leading scientific journals. He is the author of two books and one textbook.

Professor Yermachenko has been one of the founders of the journal Laser Physics, and he continues to serve as its Member of the Editorial Board. He also has been one of the initiators of the International Workshop on Laser Physics, being the Member of the Steering Committee since 1991. In 2003, he has been one of the founders of the journal Laser Physics Letters, where he is a Deputy Editor-in-Chief till the present time.

Congratulating our friend Valery Yermachenko with his Jubilee, the Editorial Board of Laser Physics wishes him good health and great success in his work! We hope that we will be so lucky to continue working with him for many years ahead.

\section{Editorial Board of Laser Physics}

